\title{
Identification of 3,4-Dihydro-2H,6H- pyrimido[1,2-c][1,3]benzothiazin-6-imine Derivatives as Novel Selective Inhibitors of Plasmodium falciparum Dihydroorotate Dehydrogenase
}

\author{
Endah Dwi Hartuti 1,2,3, Takaya Sakura ${ }^{4,5} \mathbb{D}$, Mohammed S. O. Tagod ${ }^{5}$, Eri Yoshida ${ }^{4}$, Xinying Wang ${ }^{5,6}$,

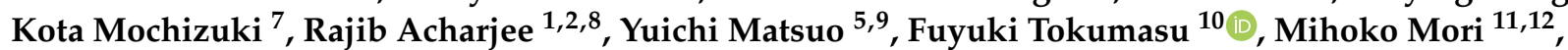 \\ Danang Waluyo $^{3}(\mathbb{D})$, Kazuro Shiomi ${ }^{12}{ }^{(D)}$, Tomoyoshi Nozaki ${ }^{6}$, Shinjiro Hamano ${ }^{1,2,13}$, Tomoo Shiba ${ }^{14}(\mathbb{D}$, \\ Kiyoshi Kita ${ }^{5,6,15}$ and Daniel Ken Inaoka ${ }^{4,5,6, *(D)}$
}

check for

updates

Citation: Hartuti, E.D.; Sakura, T.; Tagod, M.S.O.; Yoshida, E.; Wang, X.; Mochizuki, K.; Acharjee, R.; Matsuo, Y.; Tokumasu, F.; Mori, M.; et al. Identification of 3,4-Dihydro-2H,6 $\mathrm{H}$ pyrimido[1,2-c][1,3]benzothiazin-6imine Derivatives as Novel Selective Inhibitors of Plasmodium falciparum Dihydroorotate Dehydrogenase. Int. J. Mol. Sci. 2021, 22, 7236. https:// doi.org/10.3390/ijms22137236

Academic Editor:

Wieslawa Jarmuszkiewicz

Received: 3 June 2021

Accepted: 2 July 2021

Published: 5 July 2021

Publisher's Note: MDPI stays neutral with regard to jurisdictional claims in published maps and institutional affiliations.

Copyright: (c) 2021 by the authors. Licensee MDPI, Basel, Switzerland. This article is an open access article distributed under the terms and conditions of the Creative Commons Attribution (CC BY) license (https:// creativecommons.org/licenses/by/ $4.0 /)$.
1 Program for Nurturing Global Leaders in Tropical and Emerging Communicable Disease, Graduate School of Biomedical Science, Nagasaki University, Nagasaki 852-8523, Japan; endah.dwi08@yahoo.co.id (E.D.H.); rajibacharjee@cu.ac.bd (R.A.); shinjiro@nagasaki-u.ac.jp (S.H.)

2 Department of Parasitology, Institute of Tropical Medicine (NEKKEN), Nagasaki University, Nagasaki 852-8523, Japan

3 Laboratory for Biotechnology, Agency for the Assessment and Application of Technology, South Tangerang 15314, Indonesia; danang.waluyo@bppt.go.id

4 Department of Molecular Infection Dynamics, Institute of Tropical Medicine (NEKKEN), Nagasaki University, Nagasaki 852-8523, Japan; takaya.sakura@nagasaki-u.ac.jp (T.S.); erioy@nagasaki-u.ac.jp (E.Y.)

5 School of Tropical Medicine and Global Health, Nagasaki University, Nagasaki 852-8523, Japan; tagod9@hotmail.com (M.S.O.T.); wangxinying1229@hotmail.com (X.W.); ymatsuo@kumamoto-u.ac.jp (Y.M.); kitak@nagasaki-u.ac.jp (K.K.)

6 Department of Biomedical Chemistry, Graduate School of Medicine, The University of Tokyo, Tokyo 113-0033, Japan; nozaki@m.u-tokyo.ac.jp

7 Department of Immunogenetics, Institute of Tropical Medicine (NEKKEN), Nagasaki University, Nagasaki 852-8523, Japan; a7m_kota@yahoo.co.jp

8 Departement of Zoology, University of Chittagong, Chittagong 4331, Bangladesh

9 Graduate School of Life Science, Kumamoto University, Kumamoto 860-0862, Japan

10 Department of Cellular Architecture Studies, Institute of Tropical Medicine (NEKKEN), Nagasaki University, Nagasaki 852-8523, Japan; ftokumasu@nagasaki-u.ac.jp

11 Biological Resource Center, NITE, Kisarazu, Chiba 292-0818, Japan; mori-mihoko@nite.go.jp

12 Graduate School of Infection Control Sciences, Kitasato University, Tokyo 108-0072, Japan; shiomi@lisci.kitasato-u.ac.jp

13 The Joint Usage/Research Center on Tropical Disease, Institute of Tropical Medicine (NEKKEN), Nagasaki University, Nagasaki 852-8523, Japan

14 Department of Applied Biology, Graduate School of Science Technology, Kyoto Institute of Technology, Matsugasaki, Sakyo-ku, Kyoto 606-8585, Japan; tshiba@kit.ac.jp

15 Department of Host-Defense Biochemistry, Institute of Tropical Medicine (NEKKEN), Nagasaki University, Nagasaki 852-8523, Japan

* Correspondence: danielken@nagasaki-u.ac.jp; Tel.: +81-95-819-723

Abstract: Plasmodium falciparum's resistance to available antimalarial drugs highlights the need for the development of novel drugs. Pyrimidine de novo biosynthesis is a validated drug target for the prevention and treatment of malaria infection. P. falciparum dihydroorotate dehydrogenase $(\mathrm{PfDHODH})$ catalyzes the oxidation of dihydroorotate to orotate and utilize ubiquinone as an electron acceptor in the fourth step of pyrimidine de novo biosynthesis. PfDHODH is targeted by the inhibitor DSM265, which binds to a hydrophobic pocket located at the N-terminus where ubiquinone binds, which is known to be structurally divergent from the mammalian orthologue. In this study, we screened 40,400 compounds from the Kyoto University chemical library against recombinant PfDHODH. These studies led to the identification of 3,4-dihydro-2H,6H-pyrimido[1,2c][1,3]benzothiazin-6-imine and its derivatives as a new class of PfDHODH inhibitor. Moreover, the hit compounds identified in this study are selective for PfDHODH without inhibition of the human enzymes. Finally, this new scaffold of PfDHODH inhibitors showed growth inhibition activity 
against $P$. falciparum 3D7 with low toxicity to three human cell lines, providing a new starting point for antimalarial drug development.

Keywords: Plasmodium falciparum; dihydroorotate dehydrogenase; inhibitor screening; ubiquinone; antimalarial drug

\section{Introduction}

Significant morbidity and mortality caused by protozoan parasitic infection pose serious threats to global health. Among parasitic diseases, malaria is the most devastating, with approximately 409,000 deaths reported during $2019,67 \%(274,000)$ of whom were children under 5 years old from sub-Saharan Africa [1,2]. Great effort has been spent to control malaria; however, the emergence of parasites resistant to practically all antimalarial drugs hampers the control and elimination of malaria. Therefore, the development of new antimalarial drugs is needed.

The majority of malaria cases reported are caused by Plasmodium falciparum. This parasite has a complex life cycle involving intermediary (human) and definitive (mosquitoes) hosts. Once a human is infected, the sporozoites migrate to the liver, invading hepatocyte (liver stage) and differentiating into schizont-containing hepatic merozoites. The hepatic schizonts then burst and release merozoites, which then infect red blood cells. During the blood stage, parasites undergo consecutive asexual development to ring, trophozoite, and schizont stages. Mature schizonts release merozoites into the bloodstream and initiate another replication cycle. A small fraction of parasites infecting erythrocytes undergo sexual development into female and male gametocytes, which are transmitted by mosquitoes during a blood meal.

Phenotypic and target-based screenings are the two approaches to obtain active compounds, the first step towards drug development. Artemisinin and its derivatives are one successful example of phenotypic screening and were introduced in 1972 [3] as antimalarial agents with an excellent safety profile. Artemisinin-based combination therapies (ACTs) are recommended by the World Health Organization (WHO) as the first-line treatment of uncomplicated P. falciparum malaria [4]. Because of the emergence of parasites resistant to ACTs, new antimalarial agents are being developed, such as spiroindolone KAE 609 (cipargamin), ozonides (e.g., OZ439), and imidazolopiperazines (KAF 156) [5-7], which are now in the development pipeline of the Medicine for Malaria Venture [8].

It is important to note that all the antimalarial drugs in clinical use were developed by phenotypic screening against the asexual blood stages, and only a few drugs are suggested to be active against the liver or mosquito stages. A new generation of antimalarial compounds targeting proteins essential in multiple stages is now under development. So far, several targets that have been chemically and/or genetically validated have been reported, such as, proteasome, phosphatidylinositol 4-kinase (PI4K), mitochondrial electron transport chain (ETC), and pyrimidine de novo biosynthesis $[9,10]$.

The pyrimidine de novo biosynthesis pathway is an attractive antimalarial drug target. Humans can acquire pyrimidines through both de novo and salvage pathways, while the genes necessary for the salvage pathway are not present in P. falciparum [11]. Thus, P. falciparum is entirely dependent on the de novo pathway [12,13] for the supply of cellular pyrimidine. In addition, the pyrimidine de novo pathway is connected to the ETC at the level of ubiquinone through a reaction catalyzed by dihydroorotate (DHO) dehydrogenase (DHODH), the fourth and rate-limiting step of this pathway. DHODH is classified into two families (1 and 2) based on substrate/cofactor dependence and subcellular localization. Family 1 DHODHs are cytosolic enzymes, depending on the electron acceptor, and are subdivided into Families 1A and 1B. Family 1A DHODHs are homodimeric enzymes and share a single binding site for the substrate (DHO) and electron acceptor (fumarate) [14]. 
Family 1B DHODHs are heterotetrameric enzymes with long-range electron transfer from the flavin mononucleotide (FMN)-containing subunit (PyrDB) to an adjacent subunit (PyrK) containing an iron-sulfur cluster [2Fe-2S], flavin adenine dinucleotide (FAD), and an electron acceptor $\left(\mathrm{NAD}^{+}\right)$[15-18]. DHODHs belonging to Family 2 are membranebound enzymes that transfer the electrons from DHO to respiratory quinones, such as, ubiquinone, menaquinone, or rhodoquinone $[19,20]$. Family 2 enzymes are found in the plasma membrane of gram-negative bacteria and the mitochondrial inner membrane of eukaryotes.

Human DHODH (HsDHODH) is a drug target for the treatment of autoimmune diseases such as rheumatoid arthritis and psoriasis [21-23]. In general, inhibitors of bacterial, human, and plasmodial DHODHs share no cross-sensitivity [24-27]. Even between DHODHs from closely related apicomplexan parasites, such as P. falciparum (PfDHODH) and Eimeria tenella (EtDHODH), no cross-sensitivity has been observed [28]. However, a certain degree of cross-sensitivity is seen between EtDHODH and HsDHODH for two particular groups of inhibitors that are derived from ferulenol and ascofuranone [28]. Although the overall structure is shared between Family 2 DHODHs, the structure of the quinone binding site is diverse [28]. Such differences in the inhibitor binding site have been explored to design species-selective inhibitors, such as DSM265, a specific inhibitor of PfDHODH [29] with remarkable activity against the blood and liver stages of $P$. falciparum but not P. vivax [30]. Although DSM265 showed promising results in a Phase 2a study by showing rapid parasite clearance after single-dose treatment [30], it is no longer included in the Medicine for Malaria Venture (MMV) portfolio [31,32], possibly due to side effects (clinical trial identifier: NCT02450578). Thus, the identification of PfDHODH inhibitors with different chemical structures and better safety profiles than DSM265 is needed. The search for new PfDHODH inhibitors has involved natural sources, including plants and microorganisms [33].

In this study, we screened 40,400 compounds from the Kyoto University chemical library [34] to discover novel PfDHODH inhibitors that are active against the asexual blood-stage parasite. Here, we report the new chemical scaffold 3,4-dihydro- $2 \mathrm{H}, 6 \mathrm{H}$ pyrimido[1,2-c][1,3]benzothiazin-6-imine (DPBI, Figure 1a) and its analog 3,4-dihydro$2 H$-benzo[4,5]isothiazolo[2,3-a]pyrimidine (DBIP, Figure 1b) as well as their derivatives as selective PfDHODH inhibitors at a sub-micromolar to low-micromolar order with low cytotoxicity to human cells.<smiles>N=C1Sc2ccccc2C2=NCCCN12</smiles>

(a)



(b)

Figure 1. Structures of 3,4-dihydro-2H,6H-pyrimido[1,2-c][1,3]benzothiazin-6-imine (a) and 3,4dihydro-2H-benzo[4,5]isothiazolo[2,3-a]pyrimidine $(\mathbf{b})$.

\section{Results}

\subsection{Identification of DPBI and DBIP Derivatives as PfDHODH Inhibitors}

His6-SUMO-tagged PfDHODH was successfully expressed and purified from the Escherichia coli membrane. After digestion by SUMO protease, we purified the tag-free enzyme with a specific activity of $22.3 \mu \mathrm{mol} / \mathrm{min} / \mathrm{mg}\left(K_{\text {cat }}=17.5 \mathrm{~s}^{-1}\right)$, which was used for screening 40,400 compounds from the Kyoto University chemical library. The quality of our screening was evaluated by calculating the following parameters: $Z^{\prime}$-factor $(0.88 \pm 0.09)$, signal window ( $S W, 49.2 \pm 20.3$ ), signal-to-noise ratio ( $\mathrm{S} / \mathrm{N}=85.0 \pm 26.0$ ), signal-to-background 
$(\mathrm{S} / \mathrm{B}=115.3 \pm 28.6)$, and negative coefficient of variation $(\mathrm{CV}=2.38 \pm 1.85 \%)$, all of which were excellent. After the initial screening at $4.5 \mu \mathrm{M}$, we identified 43 compounds that meet the hit criteria ( $>50 \%$ inhibition), for a hit rate of $0.11 \%$ (Figure 2). According to the library policy, the chemical structures are disclosed only for the hits. After analysis of their chemical structures, we classified the hits as derivatives of DPBI or DBIP, which are listed in Tables 1-4.

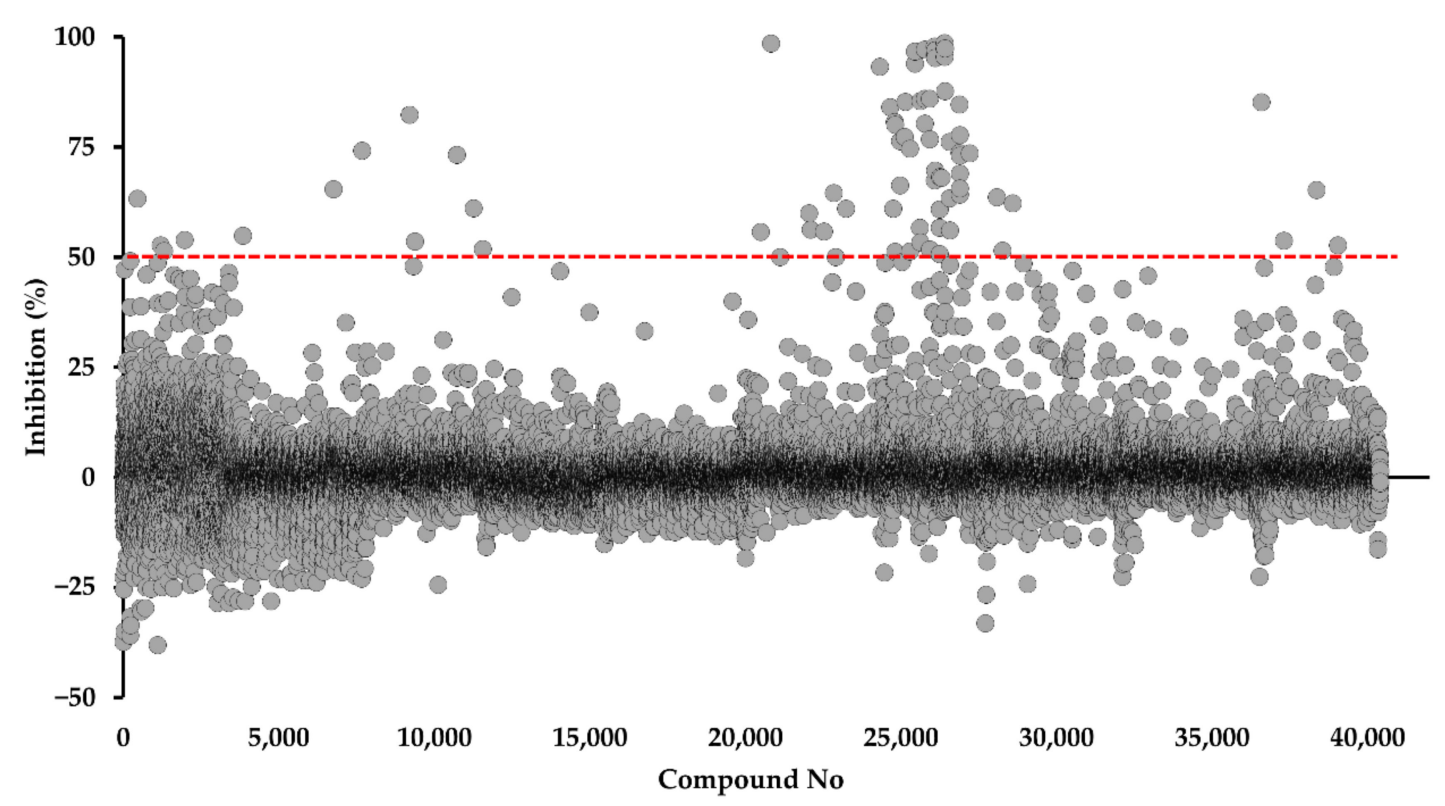

Figure 2. Screening of 40,400 compounds from Kyoto University chemical library against PfDHODH. The screening was performed at a final concentration of $4.5 \mu \mathrm{M}$. The dashed line represents the $50 \%$ inhibition threshold for the selection of hits.

\subsection{Structure-Activity Relationship of DPBI Derivatives}

Of the 43 hits obtained in this study, 27 compounds were DPBI derivatives (Tables 1 and 2 and Figure S1). The introduction of a 2-napthyl group at the $\mathrm{R}_{1}$-position of DPBI showed the highest inhibition $\left(\mathbf{1}, \mathrm{IC}_{50}=0.65 \mu \mathrm{M}\right)$ against PfDHODH. Substitution at $\mathrm{R}_{1}$ to other 2-membered rings, such as Compounds 2 to 7, did not drastically affect the $\mathrm{IC}_{50}$ s against PfDHODH ( $\mathrm{IC}_{50}$ ranging from 0.70 to $1.3 \mu \mathrm{M}$ ) as shown in Table 1. Similarly, substitution with a styrene group at $\mathrm{R}_{1}\left(\mathbf{8}, \mathrm{IC}_{50}=1.07 \mu \mathrm{M}\right)$ or a phenyl group at $\mathrm{R}_{2}(\mathbf{9}$, $\left.\mathrm{IC}_{50}=0.76 \mu \mathrm{M}\right)$ maintained the activity towards PfDHODH. Dual substitutions with benzothiophene and tert-butyl groups at $\mathrm{R}_{1}$ and $\mathrm{R}_{3}\left(10, \mathrm{IC}_{50}=3.84 \mu \mathrm{M}\right)$, respectively, resulted in a 6-fold increase in the $\mathrm{IC}_{50}$ compared to $\mathbf{1}$ (Table 1). Changing the backbone structure from DPBI to 2,3,4,6-tetrahydro-7-thia-1,5-diazatetraphen-6-imine (11) resulted in an increased $\mathrm{IC}_{50}$ to $6.42 \mu \mathrm{M}$ relative to 1 . Substitutions of the 2-naphtyl group of 1 to a phenyl group (12) had little effect on $\mathrm{IC}_{50}$ (Table 2). Additional substitutions at $\mathrm{R}_{1}, \mathrm{R}_{2}$, or $\mathrm{R}_{3}$ from Compound 12 showed modest increases in the $\mathrm{IC}_{50}$ ranging from 0.96 to $3.89 \mu \mathrm{M}$ against PfDHODH (Compounds 13 to 27; Table 2).

\subsection{Structure-Activity Relationship of DBIP Derivatives}

As a result of screening, 16 derivatives of BIP were included in the hits (Tables 3 and 4 and Figure S2). BIP derivatives listed in Table 3 having acetamido (28) or trifluoromethyl (29) substitutions at $\mathrm{R}_{1}$ showed the highest $\mathrm{IC}_{50} \mathrm{~s}$ of 18.5 and $9.71 \mu \mathrm{M}$ against PfDHODH, respectively. Other BIP derivatives with substitutions at $R_{1}$ (30 to 35$)$ or $R_{2}$ (36) inhibited PfDHODH activity stronger than 28 (Table 3). Moreover, polar substitutions on the benzene group of 30 at $R_{1}$ (37 to 39 ), $R_{2}$ (40 and 41 ), or $R_{3}$ (42 and 43 ) lowered the $\mathrm{IC}_{50}$ compared to 30 (Table 4). 
Table 1. Antimalarial activities of DPBI derivatives.

\begin{tabular}{|c|c|c|c|c|c|c|c|c|c|}
\hline \multirow{3}{*}{ Cpd } & & stitu & & \multicolumn{4}{|c|}{$\mathrm{IC}_{50}(\mu \mathrm{M})$} & \multirow{3}{*}{$\begin{array}{c}\mathrm{EC}_{50}(\mu \mathrm{M}) \\
\text { Pf3D7 }\end{array}$} & \multirow{3}{*}{$\begin{array}{c}\text { Growth at } \\
10 \mu \mathrm{M}(\%) \\
\text { Pf3D7- } \\
\text { yDHODH }\end{array}$} \\
\hline & \multirow{2}{*}{$\mathbf{R}_{1}$} & \multirow{2}{*}{$\mathbf{R}_{2}$} & \multirow{2}{*}{$\mathbf{R}_{3}$} & \multicolumn{2}{|c|}{ DHODH } & \multicolumn{2}{|c|}{$\begin{array}{l}\text { Mammalian } \\
\text { Mitochondrial }\end{array}$} & & \\
\hline & & & & Pf & Hs & CI-III & CII-III & & \\
\hline 1 & & $\mathrm{H}$ & $\mathrm{H}$ & $0.65 \pm 0.05$ & $>4.5$ & $>22.7$ & $>22.7$ & $0.43 \pm 0.18$ & $-0.62 \pm 0.07$ \\
\hline 2 & & $\mathrm{H}$ & $\mathrm{H}$ & $0.85 \pm 0.05$ & $>4.5$ & $13.9 \pm 2.14$ & $>22.7$ & $>10$ & nd \\
\hline 3 & & $\mathrm{H}$ & $\mathrm{H}$ & $1.18 \pm 0.04$ & $>4.5$ & $>22.7$ & $>22.7$ & $1.16 \pm 0.02$ & $-0.23 \pm 0.01$ \\
\hline 4 & & $\mathrm{H}$ & $\mathrm{H}$ & $0.97 \pm 0.08$ & $>4.5$ & $>22.7$ & $>22.7$ & $1.07 \pm 0.05$ & $24.0 \pm 5.76$ \\
\hline 5 & & $\mathrm{H}$ & $\mathrm{H}$ & $0.96 \pm 0.09$ & $>4.5$ & $>22.7$ & $>22.7$ & $1.13 \pm 0.05$ & $26.0 \pm 8.27$ \\
\hline 6 & & $\mathrm{H}$ & $\mathrm{H}$ & $0.70 \pm 0.04$ & $>4.5$ & $>22.7$ & $>22.7$ & $0.37 \pm 0.05$ & $104.4 \pm 0.11$ \\
\hline 7 & & $\mathrm{H}$ & $\mathrm{H}$ & $1.30 \pm 0.05$ & $>4.5$ & $>22.7$ & $>22.7$ & $0.34 \pm 0.01$ & $36.2 \pm 1.01$ \\
\hline 8 & & $\mathrm{H}$ & $\mathrm{H}$ & $1.07 \pm 0.05$ & $>4.5$ & $>22.7$ & $>22.7$ & $0.63 \pm 0.25$ & $0.12 \pm 0.21$ \\
\hline 9 & $\mathrm{H}$ & & $\mathrm{H}$ & $0.76 \pm 0.08$ & $>4.5$ & $>22.7$ & $>22.7$ & $>10$ & nd \\
\hline 10 & & $\mathrm{H}$ & $\left(\mathrm{CH}_{3}\right)_{3}$ & $3.84 \pm 0.09$ & $>4.5$ & $>22.7$ & $>22.7$ & $2.77 \pm 0.28$ & $-0.48 \pm 0.07$ \\
\hline 11 & & & $\mathrm{H}$ & $6.42 \pm 0.09$ & $>4.5$ & $>22.7$ & $>22.7$ & $>10$ & nd \\
\hline
\end{tabular}

Several derivatives that were not active against $P$. falciparum 3D7 were not assayed against transgenic 3D7-yDHODH. The IC 50 value represents the concentration of each compound that inhibits PfDHODH, HsDHODH, CI-III, and CII-III activities by $50 \%$. The EC 50 value represents the concentration of each compound that inhibits Pf3D7 growth by $50 \%$. Values and errors are averages and standard deviations of at least $\mathrm{n}=3$. Compounds listed in bold were showing $\mathrm{EC}_{50}<1 \mu \mathrm{M}$ against Pf3D7. The chemical structures are colored according to the CPK scheme (oxygen atom $=$ red; nitrogen atom $=$ blue; sulfur atom $=$ deep yellow; and fluorine atom $=$ light green). nd $=$ not determined . 
Table 2. Antimalarial activities of Compound 12 derivatives.

\begin{tabular}{|c|c|c|c|c|c|c|c|c|c|}
\hline \multirow{3}{*}{ Cpd } & \multicolumn{3}{|c|}{ Substituents } & \multicolumn{4}{|c|}{$\mathrm{IC}_{50}(\mu \mathrm{M})$} & \multirow{3}{*}{$\begin{array}{c}\mathrm{EC}_{50}(\mu \mathrm{M}) \\
\text { Pf3D7 }\end{array}$} & \multirow{3}{*}{$\begin{array}{c}\text { Growth at } \\
10 \mu \mathrm{M}(\%) \\
\text { Pf3D7- } \\
\text { yDHODH }\end{array}$} \\
\hline & \multirow[t]{2}{*}{$\mathbf{R}_{1}$} & \multirow{2}{*}{$\mathrm{R}_{2}$} & \multirow[t]{2}{*}{$\mathrm{R}_{3}$} & DHOL & & \multicolumn{2}{|c|}{$\begin{array}{l}\text { Mammalian } \\
\text { Mitochondrial }\end{array}$} & & \\
\hline & & & & Pf & Hs & CI-III & CII-III & & \\
\hline 12 & $\mathrm{H}$ & $\mathrm{H}$ & $\mathrm{H}$ & $0.68 \pm 0.05$ & $>4.5$ & $>22.7$ & $>22.7$ & $1.15 \pm 0.07$ & $-0.22 \pm 0.12$ \\
\hline 13 & & $\mathrm{H}$ & $\mathrm{H}$ & $1.22 \pm 0.05$ & $>4.5$ & $>22.7$ & $>22.7$ & $1.06 \pm 0.01$ & $70.5 \pm 0.73$ \\
\hline 14 & $\mathrm{~N} \equiv:-$ & $\mathrm{H}$ & $\mathrm{H}$ & $3.89 \pm 0.23$ & $>4.5$ & $>22.7$ & $>22.7$ & $1.21 \pm 0.04$ & $105 \pm 0.47$ \\
\hline 15 & & $\mathrm{H}$ & $\mathrm{H}$ & $2.31 \pm 0.11$ & $>4.5$ & $>22.7$ & $>22.7$ & $1.00 \pm 0.05$ & $-0.38 \pm 0.17$ \\
\hline 16 & & $\mathrm{H}$ & $\mathrm{H}$ & $1.82 \pm 0.08$ & $>4.5$ & $>22.7$ & $>22.7$ & $>10$ & nd \\
\hline 17 & & $\mathrm{H}$ & $\mathrm{H}$ & $0.96 \pm 0.07$ & $>4.5$ & $>22.7$ & $>22.7$ & $1.62 \pm 0.56$ & $-0.50 \pm 0.01$ \\
\hline 18 & & $\mathrm{H}$ & $\mathrm{H}$ & $1.43 \pm 0.06$ & $>4.5$ & $>22.7$ & $>22.7$ & $0.37 \pm 0.13$ & $2.54 \pm 0.42$ \\
\hline 19 & & $\mathrm{H}$ & $\mathrm{H}$ & $1.07 \pm 0.05$ & $>4.5$ & $>22.7$ & $>22.7$ & $0.51 \pm 0.14$ & $68.6 \pm 0.43$ \\
\hline 20 & & $\mathrm{H}$ & $\mathrm{H}$ & $1.21 \pm 0.06$ & $>4.5$ & $>22.7$ & $>22.7$ & $0.38 \pm 0.08$ & $0.45 \pm 0.74$ \\
\hline 21 & $\mathrm{H}$ & & $\mathrm{H}$ & $3.68 \pm 0.31$ & $>4.5$ & $>22.7$ & $>22.7$ & $0.85 \pm 0.12$ & $103 \pm 0.67$ \\
\hline 22 & $\mathrm{H}$ & & $\mathrm{H}$ & $1.56 \pm 0.05$ & $>4.5$ & $>22.7$ & $>22.7$ & $0.90 \pm 0.44$ & $-0.06 \pm 0.24$ \\
\hline 23 & $\mathrm{H}$ & & $\mathrm{H}$ & $1.85 \pm 0.19$ & $>4.5$ & $>22.7$ & $>22.7$ & $>10$ & nd \\
\hline 24 & $\mathrm{H}$ & $\mathrm{O}=\stackrel{0}{\mathrm{I}}=\stackrel{\mathrm{N}}{\mathrm{O}}$ & $\mathrm{H}$ & $1.94 \pm 0.07$ & $>4.5$ & $>22.7$ & $>22.7$ & $>10$ & nd \\
\hline 25 & $\mathrm{H}$ & $\mathrm{C}_{2} \mathrm{H}_{5}$ & $\mathrm{H}$ & $1.52 \pm 0.08$ & $>4.5$ & $>22.7$ & $>22.7$ & $1.77 \pm 0.83$ & $0.01 \pm 0.15$ \\
\hline 26 & $\mathrm{H}$ & & $\mathrm{H}$ & $3.49 \pm 0.21$ & $>4.5$ & $>22.7$ & $>22.7$ & $>10$ & nd \\
\hline 27 & $\mathrm{H}$ & $\mathrm{H}$ & & $3.30 \pm 0.10$ & $>4.5$ & $>22.7$ & $>22.7$ & $0.39 \pm 0.05$ & $0.25 \pm 0.04$ \\
\hline
\end{tabular}

Several derivatives that were not active against $P$. falciparum 3D7 were not assayed against transgenic $3 \mathrm{D} 7-\mathrm{yDHODH}$. The $\mathrm{IC}_{50}$ value represents the concentration of each compound that inhibits PfDHODH, HsDHODH, CI-III, and CII-III activities by $50 \%$. The EC 50 value represents the concentration of each compound that inhibits Pf3D7 growth by $50 \%$. Values and errors are averages and standard deviations of at least $\mathrm{n}=3$. Compounds listed in bold were showing $\mathrm{EC}_{50}<1 \mu \mathrm{M}$ against Pf3D7. The chemical structures color codes are described in Table $1 . \mathrm{Nd}=$ not determined. 
Table 3. Antimalarial activity of DBIP derivatives.

\begin{tabular}{|c|c|c|c|c|c|c|c|c|}
\hline \multirow{3}{*}{ Cpd } & \multicolumn{2}{|c|}{ Substituents } & \multicolumn{4}{|c|}{$\mathrm{IC}_{50}(\mu \mathrm{M})$} & \multirow{3}{*}{$\begin{array}{c}\mathrm{EC}_{50}(\mu \mathrm{M}) \\
\text { Pf3D7 }\end{array}$} & \multirow{3}{*}{$\begin{array}{c}\text { Growth at } \\
10 \mu \mathrm{M}(\%) \\
\text { Pf3D7- } \\
\text { yDHODH }\end{array}$} \\
\hline & \multirow[t]{2}{*}{$\mathbf{R}_{1}$} & \multirow[t]{2}{*}{$\mathrm{R}_{2}$} & \multicolumn{2}{|c|}{ DHODH } & \multicolumn{2}{|c|}{$\begin{array}{l}\text { Mammalian } \\
\text { Mitochondrial }\end{array}$} & & \\
\hline & & & Pf & Hs & CI-III & CII-III & & \\
\hline 28 & & $\mathrm{H}$ & $18.5 \pm 0.40$ & $>4.5$ & $>22.7$ & $>22.7$ & $>10$ & nd \\
\hline 29 & & $\mathrm{H}$ & $9.71 \pm 0.29$ & $>4.5$ & $>22.7$ & $>22.7$ & $>10$ & nd \\
\hline 30 & & $\mathrm{H}$ & $4.26 \pm 0.12$ & $>4.5$ & $>22.7$ & $>22.7$ & $9.67 \pm 5.09$ & $63.6 \pm 5.87$ \\
\hline 31 & & $\mathrm{H}$ & $1.10 \pm 0.08$ & $>4.5$ & $>22.7$ & $>22.7$ & $0.33 \pm 0.01$ & $0 \pm 0.07$ \\
\hline 32 & & $\mathrm{H}$ & $1.29 \pm 0.09$ & $>4.5$ & $>22.7$ & $>22.7$ & $1.85 \pm 0.53$ & $0.11 \pm 0.03$ \\
\hline 33 & & $\mathrm{H}$ & $1.53 \pm 0.04$ & $>4.5$ & $>22.7$ & $>22.7$ & $3.73 \pm 0.88$ & $44.1 \pm 26.2$ \\
\hline 34 & & $\mathrm{H}$ & $0.94 \pm 0.05$ & $>4.5$ & $>22.7$ & $>22.7$ & $1.64 \pm 0.35$ & $-0.1 \pm 0.28$ \\
\hline 35 & & $\mathrm{H}$ & $1.48 \pm 0.07$ & $>4.5$ & $>22.7$ & $>22.7$ & $>10$ & nd \\
\hline 36 & $\mathrm{H}$ & & $1.51 \pm 0.04$ & $>4.5$ & $>22.7$ & $>22.7$ & $4.16 \pm 0.09$ & $32.5 \pm 10.1$ \\
\hline
\end{tabular}

Several derivatives that were not active against $P$. falciparum $3 \mathrm{D} 7$ were not assayed against transgenic $3 \mathrm{D} 7-\mathrm{yDHODH}$. The $\mathrm{IC}_{50}$ value represents the concentration of each compound that inhibits PfDHODH, HsDHODH, CI-III, and CII-III activities by $50 \%$. The EC 50 value represents the concentration of each compound that inhibits Pf3D7 growth by $50 \%$. Values and errors are averages and standard deviations of at least $\mathrm{n}=3$. Compounds listed in bold were showing $\mathrm{EC}_{50}<1 \mu \mathrm{M}$ against Pf3D7. The chemical structures color codes are described in Table $1 . \mathrm{Nd}=$ not determined.

\subsection{Counter-Assays Against HsDHODH and Mammalian Complex I, II, and III Activities}

To investigate whether or not the hits obtained in this study also inhibit HsDHODH, a counter-assay was conducted using purified recombinant HsDHODH. As a result, none of the hits inhibited HsDHODH (Tables 1-4). Except for orotate derivatives, all known Family 2 DHODH inhibitors bind to the ubiquinone binding site. To test the hypothesis that the inhibitors of PfDHODH obtained in this study also bind to the ubiquinone binding site of mammalian respiratory complexes I, II, and III, inhibition assays against the activities of complexes I-III and II-III were conducted. As shown in Tables 1-4, except for 2, which mildly inhibited mammalian complex I-III activity $\left(\mathrm{IC}_{50}=13.9 \mu \mathrm{M}\right)$, the remaining hits did not inhibit the activities of mammalian complexes I-III and II-III, at least in the range tested $(0.0007$ to $22.7 \mu \mathrm{M})$ in this study.

\subsection{Antimalarial Activity of PfDHODH Inhibitors from the Kyoto University Chemical Library}

Next, in vitro antimalarial activities of the 43 hits were evaluated against $P$. falciparum 3D7 based on PfLDH/diaphorase assays. A total of 31 compounds displayed $\mathrm{EC}_{50}$ s below $10 \mu \mathrm{M}$, while the other 12 compounds did not inhibit parasite growth. From the compounds exhibiting antimalarial activity, 19 compounds showed an $\mathrm{EC}_{50}$ between 1 and $10 \mu \mathrm{M}$, and 12 compounds were below $1 \mu \mathrm{M}$ (Tables 1-4). 
Table 4. Antimalarial activity of Compound 30 derivatives.

\begin{tabular}{|c|c|c|c|c|c|c|c|c|c|}
\hline \multirow{3}{*}{ Cpd } & \multicolumn{3}{|c|}{ Substituents } & \multicolumn{4}{|c|}{$\mathrm{IC}_{50}(\mu \mathrm{M})$} & \multirow{3}{*}{$\begin{array}{c}\mathrm{EC}_{50}(\mu \mathrm{M}) \\
\text { Pf3D7 }\end{array}$} & \multirow{3}{*}{$\begin{array}{c}\text { Growth at } \\
10 \mu \mathrm{M}(\%) \\
\text { Pf3D7- } \\
\text { yDHODH }\end{array}$} \\
\hline & \multirow[t]{2}{*}{$\mathbf{R}_{1}$} & \multirow[t]{2}{*}{$\mathrm{R}_{2}$} & \multirow[t]{2}{*}{$\mathrm{R}_{3}$} & \multicolumn{2}{|c|}{ DHODH } & \multicolumn{2}{|c|}{$\begin{array}{l}\text { Mammalian } \\
\text { Mitochondrial }\end{array}$} & & \\
\hline & & & & Pf & Hs & CI-III & CII-III & & \\
\hline 37 & & $\mathrm{H}$ & $\mathrm{H}$ & $1.15 \pm 0.07$ & $>4.5$ & $>22.7$ & $>22.7$ & $2.78 \pm 0.27$ & $-0.18 \pm 0.05$ \\
\hline 38 & но-:- & $\mathrm{H}$ & $\mathrm{H}$ & $1.81 \pm 0.01$ & $>4.5$ & $>22.7$ & $>22.7$ & $>10$ & nd \\
\hline 39 & ill & $\mathrm{H}$ & $\mathrm{H}$ & $1.30 \pm 0.04$ & $>4.5$ & $>22.7$ & $>22.7$ & $1.14 \pm 0.06$ & $1.48 \pm 0.14$ \\
\hline 40 & $\mathrm{H}$ & $\prod_{0}^{0}$ & $\mathrm{H}$ & $1.43 \pm 0.02$ & $>4.5$ & $>22.7$ & $>22.7$ & $1.72 \pm 0.48$ & $-0.09 \pm 0.08$ \\
\hline 41 & $\mathrm{H}$ & но-:- & $\mathrm{H}$ & $1.44 \pm 0.05$ & $>4.5$ & $>22.7$ & $>22.7$ & $>10$ & nd \\
\hline 42 & $\mathrm{H}$ & $\mathrm{H}$ & $-0 . \therefore$ & $1.18 \pm 0.05$ & $>4.5$ & $>22.7$ & $>22.7$ & $0.54 \pm 0.22$ & $0.04 \pm 0.15$ \\
\hline 43 & $\mathrm{H}$ & $\mathrm{H}$ & $0=N^{\prime+}$ & $1.15 \pm 0.06$ & $>4.5$ & $>22.7$ & $>22.7$ & $1.11 \pm 0.08$ & $31.1 \pm 2.38$ \\
\hline
\end{tabular}

Several derivatives that were not active against $P$. falciparum 3D7 were not assayed against transgenic 3D7-yDHODH. The IC 50 value represents the concentration of each compound that inhibits PfDHODH, $\mathrm{HsDHODH}, \mathrm{CI}-\mathrm{III}$, and CII-III activities by $50 \%$. The $\mathrm{EC}_{50}$ value represents the concentration of each compound that inhibits Pf3D7 growth by $50 \%$. Values and errors are averages and standard deviations of at least $\mathrm{n}=3$. Compounds listed in bold were showing $\mathrm{EC}_{50}<1 \mu \mathrm{M}$ against Pf3D7. The chemical structures color codes are described in Table $1 . \mathrm{Nd}=$ not determined.

\subsection{Cytotoxicity Assay of Mammalian Cells}

The cytotoxicities of the hits were assessed against three different human cell lines: HDF, PANC-1, and DLD-1. A total of 5 DBIP derivative compounds, 36, 37, 40, 42, and 43, showed weak cytotoxicity (Table S1) against the normal cell line (HDF), with $\mathrm{EC}_{50}$ values of $8.38,8.43,9.16,9.77$, and $9.44 \mu \mathrm{M}$, respectively (Figure S3). None of the tested compounds affected the growth of the two cancer cell lines PANC-1 and DLD-1 (Table S1).

\subsection{Confirmation Assay against the Transgenic Parasites}

To test whether the expression of yDHODH in P. falciparum 3D7 could confer resistance to the PfDHODH inhibitors identified in this study, relative parasite growth at $10 \mu \mathrm{M}$ was analyzed. As shown in Tables 1-4, Pf3D7-yDHODH parasite showed reduced susceptibility to several compounds, $6,13,14,19,21,30$, and 43 . Some hits inhibited the growth of both wild-type and Pf3D7-yDHODH, suggesting the presence of off-target(s) in P. falciparum (Tables 1-4 and Figure S4).

\section{Discussion}

The current drugs used to treat malaria were developed by classical phenotypic screening targeting the asexual blood stage. For effective malaria eradication, antimalarial drugs targeting multiple life cycle stages are desired [35,36], such as the gametocyte (transmission-blocking activity) and/or sporozoite (chemoprophylaxis) stages, in addition to the intraerythrocytic stage. In that sense, pyrimidine de novo biosynthesis is an attractive drug target because of its essentiality in at least the asexual and sporozoite stages.

To discover selective PfDHODH inhibitors with a novel scaffold, we screened 40,400 compounds from Kyoto University chemical library. This library is open-access and composed of many original compounds and diverse scaffolds (https:/ /www.pharm. kyoto-u.ac.jp/pgcg/library.html) (accessed on 10 May 2021). Our efforts led to the identification of a new class of PfDHODH inhibitors that share DPBI and DBIP moieties. Those 
derivatives have previously been reported to inhibit the proliferation of human immunodeficiency virus (HIV) [37-42], hepatitis C virus [42,43], and herpes simplex virus [41]. The 43 PfDHODH inhibitors identified in this study showed no inhibition against the human enzyme or mammalian mitochondrial complexes I-III and II-III, except for 2, which weakly inhibited complex I-III activity (Table 1). This result suggests that those compounds have little or no effect on the ETC of host mitochondria. The majority of those inhibitors were active against $P$. falciparum 3D7 and displayed low toxicity to mammalian normal and cancer cell lines.

Family 1 DHODHs are insensitive to Family 2 DHODH inhibitors because they lack the ubiquinone binding site [44]. Hence, transgenic P. falciparum-expressing Family 1A DHODHs, such as yDHODH, are known to be resistant to PfDHODH inhibitors [45,46]. Such strains have been used to probe the mechanism of action of new antimalarials that target PfDHODH. In this study, the antimalarial activity and mechanism of action were confirmed for $6,13,14,19,21,30$, and 43 , which showed growth inhibition against 3D7 but were inactive against 3D7-yDHODH (Tables 1,2 and 4). Several derivatives were able to inhibit the growth of both 3D7 and 3D7-yDHODH strains, which were more pronounced in DBIP than DPBI derivatives, indicating the presence of additional target(s) (Tables 1-4, Figure S4).

In this study, we have identified PfDHODH inhibitors with new chemical scaffolds that inhibited the growth of the P. falciparum 3D7 strain. Further activity profiling, such as activity against multi-drug resistant strains (Dd2 or K strains), liver-stage parasites, as well as in vivo models (P. berghei) will be required for the future development of the compounds described in this study.

\section{Materials and Methods}

\subsection{Expression and Purification of Recombinant PfDHODH}

The codon-optimized PfDHODH gene, encoding amino acid residues 158 to 569 fused to a His6-SUMO tag in its N-terminus, was constructed and optimized for expression in E. coli, as recently reported [33]. Briefly, the E. coli BL21 Star (DE3) strain, harboring pETSUMO/PfDHODH, was selected in Luria-Bertani agar plates supplemented with $50 \mu \mathrm{g} / \mathrm{mL}$ kanamycin (Sigma). A single colony was inoculated onto $360 \mathrm{~mL}$ of LB medium containing the same antibiotic (pre-culture) and cultured at $37^{\circ} \mathrm{C}$ for $16 \mathrm{~h}$ with shaking at $200 \mathrm{rpm}$. The pre-culture $(60 \mathrm{~mL})$ was transferred to $600 \mathrm{~mL}$ of Terrific-Broth media supplemented with $50 \mu \mathrm{g} / \mathrm{mL}$ kanamycin in an Ultra Yield ${ }^{\circledR \circledR}$ flask (Thomson), and then cultured at $37^{\circ} \mathrm{C}$ with vigorous shaking at $200 \mathrm{rpm}$ (a total of 6 flasks). Protein expression was induced by $25 \mu \mathrm{M}$ isopropyl $\beta$-D-1-thiogalactopyranoside (IPTG, Sigma) when the optical density at $600 \mathrm{~nm}$ reached $0.6-0.8$, and then cultured for $16 \mathrm{~h}$ at $20^{\circ} \mathrm{C}$.

The subsequent purification steps were performed at $4{ }^{\circ} \mathrm{C}$. Cells were harvested by centrifugation at $5000 \times \mathrm{g}$ for $10 \mathrm{~min}$, and then resuspended in lysis buffer containing $50 \mathrm{mM}$ HEPES-NaOH (Dojindo) pH 7.6, $50 \mathrm{mM} \mathrm{NaCl}$ (Wako), $5 \mathrm{mM}$ imidazole (Wako), $20 \%(v / v)$ glycerol (Wako), and $0.25 \mathrm{mM}$ phenylmethylsulfonyl fluoride (PMSF, Wako). Suspended cells were disrupted by a French press (Ohtake) at $180 \mathrm{MPa}$, followed by centrifugation at 30,000 $\times g$ for 20 min to discard unbroken cells and debris. Triton X-100 (Roche) was mixed with a supernatant to a final concentration of $1 \%(w / v)$, stirred for $30 \mathrm{~min}$, and then further centrifuged at 40,000 $\times \mathrm{g}$ for $90 \mathrm{~min}$. The supernatant was mixed with $3 \mathrm{~mL}$ of pre-equilibrated nickel-nitriloacetic acid (Ni-NTA, Qiagen) resin and kept overnight, rotating at $10 \mathrm{rpm}$. The protein-resin mixture was centrifuged at $1500 \times g$ for $15 \mathrm{~min}$ and the resin was suspended in a minimal volume of supernatant and loaded into a gravity-flow column. Next, the column was sequentially washed with $60 \mathrm{~mL}$ of buffer A (50 mM HEPES-NaOH pH 7.6, $300 \mathrm{mM} \mathrm{NaCl}, 10 \%(v / v)$ glycerol, $0.2 \mathrm{mM}$ orotate), $60 \mathrm{~mL}$ of buffer A containing $0.05 \%(w / v)$ polyoxyethylene(9)dodecyl ether $\left(\mathrm{C}_{12} \mathrm{E}_{9}\right.$, Anatrace), and followed by $60 \mathrm{~mL}$ of buffer A containing $0.05 \% \mathrm{C}_{12} \mathrm{E}_{9}$ and $20 \mathrm{mM}$ imidazole. The bound protein was eluted with buffer A containing $0.05 \% \mathrm{C}_{12} \mathrm{E}_{9}$ and $300 \mathrm{mM}$ imidazole. The eluted fraction was concentrated using a centrifugal filter unit (Amicon Ultra-50, $50 \mathrm{kDa}$ 
molecular weight cut-off (MWCO), Millipore) at $3500 \times g$ until the final volume reached $0.5 \mathrm{~mL}$. The concentrated protein plus detergent solution was diluted with buffer A containing $0.05 \%(w / v) \mathrm{C}_{12} \mathrm{E}_{9}$ until the imidazole concentration was reduced to $75 \mathrm{mM}$.

The His6-SUMO tag was cleaved by SUMO protease at a 1:50 ratio relative to PfD$\mathrm{HODH}$ to a final volume of $40 \mathrm{~mL}$ in cleavage buffer ( $50 \mathrm{mM}$ Tris- $\mathrm{HCl} \mathrm{pH} \mathrm{8.0,0.05 \%} \mathrm{(w/v)}$ $\mathrm{C}_{12} \mathrm{E}_{9}$, and $0.2 \mathrm{mM}$ orotate) and incubated for $14 \mathrm{~h}$. Equilibrated Ni-NTA resin was added into the cleavage mix and then incubated for $2.5 \mathrm{~h}$ at $4{ }^{\circ} \mathrm{C}$, followed by loading onto a gravity-flow column. The flow-through was collected and concentrated as described above. An equal volume of cold glycerol was added to the concentrated protein, FMN was added to a final concentration of $200 \mu \mathrm{M}$, and it was stored at $-30{ }^{\circ} \mathrm{C}$ until use.

\subsection{Screening of the Kyoto University chemical Library}

The screening of 40,400 compounds was conducted in 384-well plates by adapting the end-point assay reported before [47]. First, $1 \mu \mathrm{L}$ of $200 \mu \mathrm{M}$ compound was transferred into 384-well plates using a Benchtop Multi-Pipetter EDR-384SR (Biotech Co., Ltd., Tokyo, Japan). The same volume of dimethyl sulfoxide (DMSO, Dojindo) was added to columns 1 and 2 as negative controls ( $0 \%$ inhibition), while $18 \%(w / v)$ sodium dodecyl sulfate (SDS, Wako) was added to columns 23 and 24 as positive controls (100\% inhibition). Next, $38 \mu \mathrm{L}$ of assay mix (100 mM HEPES-NaOH pH 7.5, $5 \%(v / v)$ glycerol, $150 \mathrm{mM} \mathrm{NaCl}, 0.05 \%(v / v)$ Triton X-100, $15 \mu \mathrm{M}$ decylubiquinone (dUQ, Sigma), $120 \mu \mathrm{M}$ 2,6-dichlorophenolindophenol (DCIP, Sigma), and $20 \mathrm{nM}$ PfDHODH) [28] were dispensed into all wells and mixed at $600 \mathrm{rpm}$ for $1 \mathrm{~min}$ by a MixMate ${ }^{\circledR 囚}$ (Eppendorf). The reaction was started by the addition of $5 \mu \mathrm{L}$ of $1.8 \mathrm{mM} \mathrm{L-DHO}$ (Sigma) as the substrate and mixed as described above for $20 \mathrm{~s}$. The absorbance at $600 \mathrm{~nm}$ was recorded using a SpectraMax ${ }^{\circledR \circledR}$ Paradigm ${ }^{\circledR \circledR}$ Multi-Mode Microplate Reader (Molecular Devices) before ( $\mathrm{t} 0$ ) and after $20 \mathrm{~min}$ ( $\mathrm{t} 20$ ) incubation at room temperature. The readings at $\mathrm{t} 0$ were subtracted from $\mathrm{t} 20$, and PfDHODH inhibition was calculated as the inhibition relative to the negative and positive controls in a single-point assay. Hits were defined as compounds inhibiting more than 50\% of PfDHODH activity at $4.5 \mu \mathrm{M}$. The quality of the screening system was evaluated by calculating statistical parameters: Z'-factor, $\mathrm{S} / \mathrm{N}, \mathrm{S} / \mathrm{B}, \mathrm{SW}$, and $\mathrm{CV}$, as previously reported $[48,49]$. The $\mathrm{IC}_{50}$ values of the hit compounds were determined using the same assay system containing serial dilutions of each compound in triplicates $(22.7,6.8,2.27,0.68,0.227,0.068,0.023$, 0.007, 0.002, $0.0007 \mu \mathrm{M}$ ) using GraphPad Prism 8.0 software (GraphPad Software Inc., San Diego, CA, USA).

\subsection{HsDHODH Assay}

Selected hit compounds from PfDHODH screening were tested for potential inhibition against HsDHODH at $4.5 \mu \mathrm{M}$. The HsDHODH used in this study was purified as previously reported [50]. The HsDHODH assay was performed similarly to that for PfDHODH, but in an assay mix consisting of $50 \mathrm{mM}$ Tris- $\mathrm{HCl} \mathrm{pH} 8.0,0.1 \%(v / v)$ Triton X-100, $2 \mathrm{mM}$ potassium cyanide (KCN, Wako), $60 \mu \mathrm{M}$ dUQ, and $120 \mu \mathrm{M}$ DCIP, with the reaction started by the addition of $200 \mu \mathrm{M} \mathrm{L-DHO}$ (final concentration) in triplicate. For this assay, DMSO was used as a negative control and $10 \mu \mathrm{M}$ of lapachol was used as a positive control $(100 \%$ inhibition). The relative inhibition was calculated as described above.

\subsection{Mammalian Complex I, II, and III Activity Assays}

Bovine heart mitochondria were prepared as previously described [50-52]. The $\mathrm{NADH}$-cytochrome $c$ reductase (complexes I-III) and succinate-cytochrome $c$ reductase (complexes II-III) activities were assayed in 384-well plates following an established protocol [53-56] with small modifications. Complex I-III activity was assayed in a reaction mix containing $50 \mathrm{mM}$ phosphate buffer $\mathrm{pH} 7.4,2 \mathrm{mM} \mathrm{KCN}, 200 \mu \mathrm{M}$ cytochrome $c$ (cytochrome $c$ from horse heart, Nacalai tesque), and $15 \mu \mathrm{g} / \mathrm{mL}$ mitochondria. Plates containing $1 \mu \mathrm{L}$ serial dilutions of PfDHODH inhibitors were prepared and mixed with $38 \mu \mathrm{L}$ of the reaction mix, as described above. The reaction was started by the addition of $5 \mu \mathrm{L}$ of 
2.6 mM NADH, and the assay was performed as described for PfDHODH, but at $550 \mathrm{~nm}$ and with 15 min of incubation. Complex II-III activity was assayed similarly to complex I-III activity but with $100 \mu \mathrm{M}$ cytochrome $c$ and $25 \mu \mathrm{g} / \mathrm{mL}$ mitochondria, and the reaction was started by $10 \mathrm{mM}$ succinate. For both assays, DMSO and $5 \mu \mathrm{M}$ ascochlorin were used as negative and positive controls, respectively. Assays were performed in triplicate.

\subsection{In vitro Antimalarial Assay}

This assay was conducted using human red blood cells (RBC) following the guidelines of the ethics committee of Nagasaki University (permission no. 19). Human RBC was obtained from the Japanese Red Cross Society. The P. falciparum 3D7 strain was cultured in 2\% hematocrit type O human RBC in RPMI-1640 medium (Gibco) supplemented with 23.8 $\mathrm{mM}$ sodium bicarbonate (Wako), $50 \mathrm{mg} / \mathrm{L}$ hypoxanthine (Wako), $25 \mathrm{mg} / \mathrm{L}$ gentamycin (Sigma), and 0.5\% (w/v) AlbuMAX ${ }^{\circledR}$ II (Gibco) under a 5\% $\mathrm{O}_{2}, 5 \% \mathrm{CO}_{2}$, and 90\% $\mathrm{N}_{2}$ atmosphere at $37^{\circ} \mathrm{C}$. Parasites were synchronized with 5\% (w/v) D-sorbitol (Wako).

Synchronized ring-stage parasites at $0.3 \%$ parasitemia and $2 \%$ hematocrit were cultured in a 384-well plate at $25 \mu \mathrm{L}$ with test compounds at a final concentration in the range of 0.0003 to $10 \mu \mathrm{M}$ with a fixed DMSO concentration of $0.4 \%(v / v)$. Parasite growth was monitored by the diaphorase-coupled P. falciparum lactate dehydrogenase (PfLDH) assay, as previously described $[57,58]$. After $72 \mathrm{~h}, 70 \mu \mathrm{L}$ of the assay solution $(150 \mathrm{mM}$ lithium L-lactate (Wako), $0.05 \mathrm{mg} / \mathrm{mL}$ 3-acetylpyridine adenine dinucleotide (Oriental Yeast Co., Ltd., Tokyo, Japan), $0.2 \mathrm{mg} / \mathrm{mL}$ nitro blue tetrazolium (Wako), 1 unit/mL diaphorase, and $100 \mathrm{mM}$ Tris- $\mathrm{HCl} \mathrm{pH}$ 8.0) were mixed with the parasite culture and incubated at room temperature for $40 \mathrm{~min}$, and the generated nitro blue formazan was measured at $650 \mathrm{~nm}$ using a SpectraMax ${ }^{\circledR}$ Paradigm ${ }^{\circledR}$ Multi-Mode Microplate Reader. The first and second columns contained $0.4 \%(v / v)$ DMSO as a negative control, and the 23rd and 24th columns had a mixture of $1 \mu \mathrm{M}$ atovaquone and artemisinin as a positive control. The $\mathrm{EC}_{50}$ was calculated using GraphPad Prism 8.0 software from the mean of quadruplets values.

\subsection{Cytotoxicity Assays of Mammalian Cells}

Human dermal fibroblast cells (HDF, Zenbio, Inc., Durham, NC, USA) were cultured in Dulbecco's Modified Eagle Medium/Nutrient Mixture F-12 medium (DMEM/F12, Gibco), human pancreatic carcinoma cells (PANC-1, DS Pharma Biomedical, Co., Ltd.) were cultured in DMEM (Gibco), and human colorectal adenocarcinoma cells (DLD-1, Taiho Pharmaceutical Company) were cultured in RPMI-1640 medium (FUJIFILM Wako Pure Chemicals). The culture mediums were supplemented with $10 \%(v / v)$ heat-inactivated fetal bovine serum (Gibco) and the cells were maintained at $37^{\circ} \mathrm{C}$ under $5 \% \mathrm{CO}_{2}$.

HDF, PANC-1, and DLD-1 were seeded at $2.5 \times 10^{4}$ cells/well on a 96-well plate and incubated at $37^{\circ} \mathrm{C}$ under $5 \% \mathrm{CO}_{2}$ overnight. The cells were then washed with PBS and the medium was replaced with $99 \mu \mathrm{L}$ of fresh media. Then, $1 \mu \mathrm{L}$ of the compounds or DMSO was added to the respective wells. As controls, wells containing $1 \%(v / v)$ DMSO in column 1 and wells containing only the culture medium in column 12 were used as the negative and positive controls, respectively. After $48 \mathrm{~h}$ of incubation, the cells were washed with PBS, and $99 \mu \mathrm{L}$ of fresh media was replaced, followed by the addition of $10 \mu \mathrm{L}$ of Cell Counting Kit-8 (Dojindo) to each well. After $3 \mathrm{~h}$ of incubation, the absorbance was measured at $450 \mathrm{~nm}$ using a SpectraMax ${ }^{\circledR}{ }^{\circledR}$ Paradigm ${ }^{\circledR}{ }^{\circledR}$ Multi-Mode microplate Reader. The calculation of cell viability in the test well was based on the absorbance of control wells according to the manufacturer's protocol. The mean of quadruplet values was used to calculate the $\mathrm{CC}_{50}$ using GraphPad Prism 8.0 software.

\subsection{Generation of Transgenic Parasite}

The P. falciparum 3D7 strain expressing the cytosolic yeast DHODH (3D7-yDHODH) was prepared as follows. pHHyDHODH-GFP plasmid (Kerafast, Boston, MA, USA) was transfected to the P. falciparum 3D7 strain following the established transfection method [59]. Briefly, $50 \mu \mathrm{g}$ of plasmid dissolved in cytomix solution $(120 \mathrm{mM} \mathrm{KCl}, 0.15 \mathrm{mM} \mathrm{CaCl}$, 
$10 \mathrm{mM} \mathrm{K}_{2} \mathrm{HPO}_{4} / \mathrm{KH}_{2} \mathrm{PO}_{4} \mathrm{pH}$ 7.6, $25 \mathrm{mM}$ HEPES-KOH pH 7.6, $2 \mathrm{mM}$ ethylene glycolbis( $\beta$-aminoethyl ether)- $N, N, N^{\prime}, N^{\prime}$-tetraacetic acid (EGTA, Dojindo), and $5 \mathrm{mM}$ magnesium chloride (Wako)) was transfected into the red blood cells by the Gene Pulser Xcell (Bio-Rad). Percoll-sorbitol synchronized parasites were mixed with red blood cells containing plasmid and maintained under $5 \mathrm{nM}$ WR99210 for 2 weeks. The growth of resistant parasites against DSM265 and atovaquone, as PfDHODH and complex III inhibitors respectively, was confirmed by PfLDH/diaphorase assay. A total of $10 \mu \mathrm{M}$ PfDHODH inhibitors were tested against wild-type 3D7 and 3D7-yDHODH following the method described above in triplicate. The significance of difference between the inhibition of the two parasite strains was evaluated by Student's $t$-test (Figure S4).

\section{Conclusions}

In this work, 40,400 compounds from the Kyoto University chemical library were screened against PfDHODH. Several quality control parameters were calculated in every assay plate, indicating excellent performance of our screening. The reproducibility of inhibition was further confirmed by the dose-response assay and $\mathrm{IC}_{50}$ determination. We successfully identified new classes of PfDHODH inhibitor harboring DPBI and DBIP moieties with growth inhibition activity against the asexual stage of P. falciparum 3D7. As DHODH does not seem to be essential in sexual stages, future studies will focus on the activity of our compounds against the liver stage parasite. Moreover, the compounds identified in this study are selective for PfDHODH and displayed low toxicity in several human cell lines, providing a new starting point for future antimalarial drug development.

Supplementary Materials: The following are available online at https: / www.mdpi.com/article / 10.3390 /ijms22137236/s1. Figure S1: The inhibitory activity of DPBI derivatives against PfDHODH and their chemical structure; Figure S2: The inhibitory activity of DBIP derivatives against PfDHODH and their chemical structures; Figure S3: Normalized normal cell line (HDF) viability after 48 h; Figure S4: Antimalarial activity of PfDHODH inhibitors against P. falciparum 3D7 and 3D7-yDHODH at $10 \mu \mathrm{M}$. Data are presented as the mean $\pm \mathrm{SD}(\mathrm{n}=3)$. Significance of difference between the two parasites was tested by Student's $t$-test. The asterisk marks a significant difference at the following levels: ${ }^{*}=p<0.05,{ }^{* *}=p<0.01,{ }^{* * *}=p<0.001,{ }^{* * * *}=p<0.0001$; Table S1: Cytotoxicity assays of DPBI and DBIP derivatives against human cell lines (HDF, PANC-1, and DLD-1).

Author Contributions: Conceptualization, D.K.I., F.T., K.K., M.M., T.S. (Tomoo Shiba) and S.H.; methodology, D.K.I.; investigation, E.D.H., T.S. (Takaya Sakura), M.S.O.T., E.Y. and D.K.I.; resources, T.S. (Takaya Sakura), X.W., K.M., R.A., Y.M. and E.D.H.; data curation, E.D.H., T.S. (Takaya Sakura), M.S.O.T. and E.Y.; writing-original draft preparation, E.D.H., T.S. (Takaya Sakura) and M.S.O.T.; writing-review and editing, E.D.H., D.K.I., T.S. (Takaya Sakura) and S.H.; supervision, D.K.I., S.H., K.K., K.S. and D.W.; funding acquisition, D.K.I., T.N., T.S. (Tomoo Shiba), T.S. (Takaya Sakura) and K.K. All authors have read and agreed to the published version of the manuscript.

Funding: This work was supported in part by grants for infectious disease control from the Science and Technology Research Partnership for Sustainable Development (SATREPS) no. 10000284 to K.K. and no. 14425718 to D.K.I. and T.N., and the Japanese Initiative for Progress of Research on Infectious Diseases for Global Epidemics JP18fm0208027 to D.K.I. and T.S. (Tomoo Shiba); and JP18fm0208020 to D.K.I.; a grants-in-aid for research on emerging and re-emerging infectious diseases no. 17929833 to K.K. and T.N. and no. 20314363 to D.K.I. and T.N. from the Agency for Medical Research and Development (AMED); a grant-in-aid for Scientific Research on Priority Areas no. 18073004 to K.K.; a Creative Scientific Research Grant no. 18GS0314 to K.K. from the Japan Society for the Promotion of Science; grants-in-aid for Scientific Research (A) 20H00620 to D.K.I., (B) 16K19114 and 19H03436 to K.K. and D.K.I., and (C) 19K07523 to D.K.I.; a grant from the Leading Initiative for Excellent Young Researchers (LEADER) no. 16811362 to D.K.I. and a grant-in-aid for early-career Scientists no. 19K16719 to T.S (Takaya Sakura) from the Japanese Ministry of Education, Science, Culture, Sports and Technology (MEXT).

Institutional Review Board Statement: Not applicable.

Informed Consent Statement: Not applicable. 


\section{Data Availability Statement: Not applicable.}

Acknowledgments: The authors thank the Program for Nurturing Global Leaders in Tropical and Emerging Communicable Diseases, Graduate School of Biomedical Sciences, Nagasaki University, and the Japanese Red Cross Society for providing human RBC.

Conflicts of Interest: The authors declare no conflict of interest.

\section{References}

1. UNICEF. Malaria in Africa. Available online: https://data.unicef.org/topic/child-health/malaria/ (accessed on 13 November 2020).

2. World Health Organization (WHO). World Malaria Report 2020; World Health Organization (WHO): Geneva, Switzerland, 2020.

3. Maude, R.J.; Woodrow, C.J.; White, L.J. Artemisinin antimalarials: Preserving the "magic bullet". Drug Dev. Res. 2010, 71, 12-19. [CrossRef]

4. World Health Organization (WHO). Guidelines for the Treatment of Malaria, 3rd ed.; World Health Organization (WHO): Geneva, Switzerland, 2015.

5. Ashley, E.A.; Phyo, A.P. Drugs in development for malaria. Drugs 2018, 78, 861-879. [CrossRef] [PubMed]

6. Burrows, J.N.; Duparc, S.; Gutteridge, W.E.; van Huijsduijnen, R.H.; Kaszubska, W.; Macintyre, F.; Mazzuri, S.; Möhrle, J.J.; Wells, T.N.C. New developments in anti-malarial target candidate and product profiles. Malar. J. 2017, 16, 26. [CrossRef]

7. Wells, T.N.; van Huijsduijnen, R.H.; van Voorhis, W.C. Malaria medicines: A glass half full? Nat. Rev. Drug Discov. 2015, 14, 424-442. [CrossRef]

8. Medicine for Malaria Venture. MMV Annual Report. 2019. Available online: https://www.mmv.org/newsroom/publications/ mmv-annual-report-2019 (accessed on 25 May 2021).

9. Blasco, B.; Leroy, D.; Fidock, D.A. Antimalarial drug resistance: Linking Plasmodium falciparum parasite biology to the clinic. Nat. Med. 2017, 23, 917-928. [CrossRef] [PubMed]

10. Belete, T.M. Recent progress in the development of new antimalarial drugs with novel targets. Drug Des. Devel. Ther. 2020, 14, 3875-3889. [CrossRef] [PubMed]

11. Gardner, M.J.; Hall, N.; Fung, E.; White, O.; Berriman, M.; Hyman, R.W.; Carlton, J.M.; Pain, A.; Nelson, K.E.; Bowman, S.; et al. Genome sequence of the human malaria parasite Plasmodium falciparum. Nature 2002, 419, 498-511. [CrossRef] [PubMed]

12. Krungkrai, S.R.; Krungkrai, J. Insights into the pyrimidine biosynthetic pathway of human malaria parasite Plasmodium falciparum as chemotherapeutic target. Asian Pac. J. Trop. Med. 2016, 9, 525-534. [CrossRef]

13. Hyde, J.E. Targeting purine and pyrimidine metabolism in human apicomplexan parasites. Curr. Drug Targets 2007, 8, 31-47. [CrossRef]

14. Björnberg, O.; Jordan, D.B.; Palfey, B.A.; Jensen, K.F. Dihydrooxonate is a substrate of dihydroorotate dehydrogenase (DHOD) providing evidence for involvement of cysteine and serine residues in base catalysis. Arch. Biochem. Biophys. 2001, 391, 286-294. [CrossRef]

15. Marcinkeviciene, J.; Tinney, L.M.; Wang, K.H.; Rogers, M.J.; Copeland, R.A. Dihydroorotate dehydrogenase B of Enterococcus faecalis. Characterization and insights into chemical mechanism. Biochemistry 1999, 38, 13129-13137. [CrossRef]

16. Malmquist, N.A.; Gujjar, R.; Rathod, P.K.; Phillips, M.A. Analysis of flavin oxidation and electron-transfer inhibition in Plasmodium falciparum dihydroorotate dehydrogenase. Biochemistry 2008, 47, 2466-2475. [CrossRef]

17. Nielsen, F.S.; Andersen, P.S.; Jensen, K.F. The B form of dihydroorotate dehydrogenase from Lactococcus lactis consists of two different subunits, encoded by the pyrDb and pyrK genes, and contains FMN, FAD, and [FeS] redox centers. J. Biol. Chem. 1996, 271, 29359-29365. [CrossRef]

18. Rowland, P.; Nørager, S.; Jensen, K.F.; Larsen, S. Structure of dihydroorotate dehydrogenase B: Electron transfer between two flavin groups bridged by an iron-sulphur cluster. Structure 2000, 8, 1227-1238. [CrossRef]

19. Sarewicz, M.; Osyczka, A. Electronic connection between the quinone and cytochrome $c$ redox pools and its role in regulation of mitochondrial electron transport and redox signaling. Physiol. Rev. 2015, 95, 219-243. [CrossRef]

20. Campbell, A.R.M.; Titus, B.R.; Kuenzi, M.R.; Rodriguez-Perez, F.; Brunsch, A.D.L.; Schroll, M.M.; Owen, M.C.; Cronk, J.D.; Anders, K.R.; Shepherd, J.N. Investigation of candidate genes involved in the rhodoquinone biosynthetic pathway in Rhodospirillum rubrum. PLoS ONE 2019, 14, e0217281. [CrossRef]

21. Schattenkirchner, M. The use of leflunomide in the treatment of rheumatoid arthritis: An experimental and clinical review. Immunopharmacology 2000, 47, 291-298. [CrossRef]

22. Abdel-Magid, A.F. Use of Dihydroorotate dehydrogenase inhibitors for treatment of autoimmune diseases and cancer. ACS Med. Chem. Lett. 2020, 11, 2072-2074. [CrossRef] [PubMed]

23. Zeng, F.; Li, S.; Yang, G.; Luo, Y.; Qi, T.; Liang, Y.; Yang, T.; Zhang, L.; Wang, R.; Zhu, L.; et al. Design, synthesis, molecular modeling, and biological evaluation of acrylamide derivatives as potent inhibitors of human dihydroorotate dehydrogenase for the treatment of rheumatoid arthritis. Acta Pharm. Sin. B 2021, 11, 795-809. [CrossRef] [PubMed]

24. Copeland, R.A.; Marcinkeviciene, J.; Haque, T.S.; Kopcho, L.M.; Jiang, W.; Wang, K.; Ecret, L.D.; Sizemore, C.; Amsler, K.A.; Foster, L.; et al. Helicobacter pylori-selective antibacterials based on inhibition of pyrimidine biosynthesis. J. Biol. Chem. 2000, 275, 33373-33378. [CrossRef] [PubMed] 
25. Ohishi, T.; Inaoka, D.K.; Kita, K.; Kawada, M. Dihydroorotate dehydrogenase as a target for the development of novel Helicobacter pylori-specific antimicrobials. Chem. Pharm. Bull. 2018, 66, 239-242. [CrossRef] [PubMed]

26. Knecht, W.; Löffler, M. Species-related inhibition of human and rat dihydroorotate dehydrogenase by immunosuppressive isoxazol and cinchoninic acid derivatives. Biochem. Pharmacol. 1998, 56, 1259-1264. [CrossRef]

27. Chen, S.F.; Perrella, F.W.; Behrens, D.L.; Papp, L.M. Inhibition of dihydroorotate dehydrogenase activity by brequinar sodium. Cancer Res. 1992, 52, 3521-3527. [PubMed]

28. Sato, D.; Hartuti, E.D.; Inaoka, D.K.; Sakura, T.; Amalia, E.; Nagahama, M.; Yoshioka, Y.; Tsuji, N.; Nozaki, T.; Kita, K.; et al. Structural and biochemical features of Eimeria tenella dihydroorotate dehydrogenase, a potential drug target. Genes 2020, 11, 1468. [CrossRef]

29. Phillips, M.A.; White, K.L.; Kokkonda, S.; Deng, X.; White, J.; El Mazouni, F.; Marsh, K.; Tomchick, D.R.; Manjalanagara, K.; Rudra, K.R.; et al. A triazolopyrimidine-based dihydroorotate dehydrogenase inhibitor with improved drug-like properties for treatment and prevention of malaria. ACS Infect. Dis. 2016, 2, 945-957. [CrossRef]

30. Llanos-Cuentas, A.; Casapia, M.; Chuquiyauri, R.; Hinojosa, J.-C.; Kerr, N.; Rosario, M.; Toovey, S.; Arch, R.H.; Phillips, M.A.; Rozenberg, F.D.; et al. Antimalarial activity of single-dose DSM265, a novel Plasmodium dihydroorotate dehydrogenase inhibitor, in patients with uncomplicated Plasmodium falciparum or Plasmodium vivax malaria infection: A proof-of-concept, open-label, phase 2a study. Lancet Infect. Dis. 2018, 18, 874-883. [CrossRef]

31. Medicine for Malaria Venture. MMV-Supported Projects. Available online: https://www.mmv.org/research-development/mmvsupported-projects (accessed on 10 May 2021).

32. Duffey, M.; Blasco, B.; Burrows, J.N.; Wells, T.N.C.; Fidock, D.A.; Leroy, D. Assessing risks of Plasmodium falciparum resistance to select next-generation antimalarials. Trends Parasitol. 2021, in press. [CrossRef]

33. Pramisandi, A.; Dobashi, K.; Mori, M.; Nonaka, K.; Matsumoto, A.; Tokiwa, T.; Higo, M.; Kristiningrum; Amalia, E.; Nurkanto, A.; et al. Microbial inhibitors active against Plasmodium falciparum dihydroorotate dehydrogenase derived from an Indonesian soil fungus, Talaromyces pinophilus BioMCC-f.T.3979. J. Gen. Appl. Microbiol. 2020, 66, 273-278. [CrossRef] [PubMed]

34. Pharmacogenomics/Chemogenomics Drug Discovery Core Lab, Graduate School of Pharmaceutical Sciences, Kyoto University. Compound Library. Available online: https://www.pharm.kyoto-u.ac.jp/pgcg/library.html (accessed on 10 May 2021).

35. Favuzza, P.; de Lera Ruiz, M.; Thompson, J.K.; Triglia, T.; Ngo, A.; Steel, R.W.J.; Vavrek, M.; Christensen, J.; Healer, J.; Boyce, C.; et al. Dual plasmepsin-targeting antimalarial agents disrupt multiple stages of the malaria parasite life cycle. Cell Host Microbe 2020, 27, 642-658.e612. [CrossRef]

36. Leshabane, M.; Dziwornu, G.A.; Coertzen, D.; Reader, J.; Moyo, P.; van der Watt, M.; Chisanga, K.; Nsanzubuhoro, C.; Ferger, R.; Erlank, E.; et al. Benzimidazole derivatives are potent against multiple life cycle stages of Plasmodium falciparum malaria parasites. ACS Infect. Dis. 2021, in press. [CrossRef]

37. Mizuhara, T.; Oishi, S.; Ohno, H.; Shimura, K.; Matsuoka, M.; Fujii, N. Structure-activity relationship study of pyrimido[1,2c][1,3]benzothiazin-6-imine derivatives for potent anti-HIV agents. Bioorg. Med. Chem. 2012, 20, 6434-6441. [CrossRef] [PubMed]

38. Okazaki, S.; Oishi, S.; Mizuhara, T.; Shimura, K.; Murayama, H.; Ohno, H.; Matsuoka, M.; Fujii, N. Investigations of possible prodrug structures for 2-(2-mercaptophenyl)tetrahydropyrimidines: Reductive conversion from anti-HIV agents with pyrimidobenzothiazine and isothiazolopyrimidine scaffolds. Org. Biomol. Chem. 2015, 13, 4706-4713. [CrossRef]

39. Okazaki, S.; Mizuhara, T.; Shimura, K.; Murayama, H.; Ohno, H.; Oishi, S.; Matsuoka, M.; Fujii, N. Identification of anti-HIV agents with a novel benzo[4,5]isothiazolo[2,3-a]pyrimidine scaffold. Bioorg. Med. Chem. 2015, 23, 1447-1452. [CrossRef] [PubMed]

40. Mizuhara, T.; Oishi, S.; Ohno, H.; Shimura, K.; Matsuoka, M.; Fujii, N. Design and synthesis of biotin- or alkyne-conjugated photoaffinity probes for studying the target molecules of PD 404182. Bioorg. Med. Chem. 2013, 21, 2079-2087. [CrossRef] [PubMed]

41. Chamoun-Emanuelli, A.M.; Bobardt, M.; Moncla, B.; Mankowski, M.K.; Ptak, R.G.; Gallay, P.; Chen, Z. Evaluation of PD 404,182 as an anti-HIV and anti-herpes simplex virus microbicide. Antimicrob. Agents Chemother. 2014, 58, 687-697. [CrossRef] [PubMed]

42. Chamoun, A.M.; Chockalingam, K.; Bobardt, M.; Simeon, R.; Chang, J.; Gallay, P.; Chen, Z. PD 404,182 is a virocidal small molecule that disrupts hepatitis C virus and human immunodeficiency virus. Antimicrob. Agents Chemother. 2012, 56, 672-681. [CrossRef] [PubMed]

43. Chockalingam, K.; Simeon, R.L.; Rice, C.M.; Chen, Z. A cell protection screen reveals potent inhibitors of multiple stages of the hepatitis C virus life cycle. Proc. Natl. Acad. Sci. USA 2010, 107, 3764-3769. [CrossRef]

44. Liu, S.; Neidhardt, E.A.; Grossman, T.H.; Ocain, T.; Clardy, J. Structures of human dihydroorotate dehydrogenase in complex with antiproliferative agents. Structure 2000, 8, 25-33. [CrossRef]

45. Ganesan, S.M.; Morrisey, J.M.; Ke, H.; Painter, H.J.; Laroiya, K.; Phillips, M.A.; Rathod, P.K.; Mather, M.W.; Vaidya, A.B. Yeast dihydroorotate dehydrogenase as a new selectable marker for Plasmodium falciparum transfection. Mol. Biochem. Parasitol. 2011, 177, 29-34. [CrossRef]

46. Painter, H.J.; Morrisey, J.M.; Mather, M.W.; Vaidya, A.B. Specific role of mitochondrial electron transport in blood-stage Plasmodium falciparum. Nature 2007, 446, 88-91. [CrossRef]

47. Baldwin, J.; Michnoff, C.H.; Malmquist, N.A.; White, J.; Roth, M.G.; Rathod, P.K.; Phillips, M.A. High-throughput screening for potent and selective inhibitors of Plasmodium falciparum dihydroorotate dehydrogenase. J. Biol. Chem. 2005, 280, 21847-21853. [CrossRef] [PubMed]

48. Sui, Y.; Wu, Z. Alternative statistical parameter for high-throughput screening assay quality assessment. J. Biomol. Screen. 2007, 12, 229-234. [CrossRef] 
49. Shun, T.Y.; Lazo, J.S.; Sharlow, E.R.; Johnston, P.A. Identifying actives from HTS data sets: Practical approaches for the selection of an appropriate HTS data-processing method and quality control review. J. Biomol. Screen. 2011, 16, 1-14. [CrossRef]

50. Miyazaki, Y.; Inaoka, D.K.; Shiba, T.; Saimoto, H.; Sakura, T.; Amalia, E.; Kido, Y.; Sakai, C.; Nakamura, M.; Moore, A.L.; et al Selective cytotoxicity of dihydroorotate dehydrogenase inhibitors to human cancer cells under hypoxia and nutrient-deprived conditions. Front. Pharmacol. 2018, 9, 997. [CrossRef]

51. Kita, K.; Takamiya, S.; Furushima, R.; Ma, Y.-C.; Suzuki, H.; Ozawa, T.; Oya, H. Electron-transfer complexes of Ascaris suum muscle mitochondria. III. Composition and fumarate reductase activity of complex II. Biochim. Biophy. Acta Bioenerg. 1988, 935, 130-140. [CrossRef]

52. Takamiya, S.; Furushima, R.; Oya, H. Electron-transfer complexes of Ascaris suum muscle mitochondria. II. Succinate-coenzyme Q reductase (complex II) associated with substrate-reducible cytochrome b-558. Biochim. Biophys. Acta 1986, 848, 99-107. [CrossRef]

53. Matsubayashi, M.; Inaoka, D.K.; Komatsuya, K.; Hatta, T.; Kawahara, F.; Sakamoto, K.; Hikosaka, K.; Yamagishi, J.; Sasai, K.; Shiba, T.; et al. Novel characteristics of mitochondrial electron transport chain from Eimeria tenella. Genes 2019, 10, 29. [CrossRef]

54. Wen, Y.; Li, W.; Poteet, E.C.; Xie, L.; Tan, C.; Yan, L.J.; Ju, X.; Liu, R.; Qian, H.; Marvin, M.A.; et al. Alternative mitochondrial electron transfer as a novel strategy for neuroprotection. J. Biol. Chem. 2011, 286, 16504-16515. [CrossRef] [PubMed]

55. Takamiya, S.; Furushima, R.; Oya, H. Electron transfer complexes of Ascaris suum muscle mitochondria: I. Characterization of $\mathrm{NADH}$-cytochrome c reductase (complex I-III), with special reference to cytochrome localization. Mol. Biochem. Parasitol. 1984, 13, 121-134. [CrossRef]

56. Miyadera, H.; Amino, H.; Hiraishi, A.; Taka, H.; Murayama, K.; Miyoshi, H.; Sakamoto, K.; Ishii, N.; Hekimi, S.; Kita, K. Altered quinone biosynthesis in the long-lived clk-1 mutants of Caenorhabditis elegans. J. Biol. Chem. 2001, 276, $7713-7716$. [CrossRef] [PubMed]

57. Hartuti, E.D.; Inaoka, D.K.; Komatsuya, K.; Miyazaki, Y.; Miller, R.J.; Xinying, W.; Sadikin, M.; Prabandari, E.E.; Waluyo, D.; Kuroda, M.; et al. Biochemical studies of membrane bound Plasmodium falciparum mitochondrial L-malate:quinone oxidoreductase, a potential drug target. Biochim. Biophys. Acta Bioenerg. 2018, 1859, 191-200. [CrossRef] [PubMed]

58. Wang, X.; Miyazaki, Y.; Inaoka, D.K.; Hartuti, E.D.; Watanabe, Y.I.; Shiba, T.; Harada, S.; Saimoto, H.; Burrows, J.N.; Benito, F.J.G.; et al. Identification of Plasmodium falciparum mitochondrial malate: Quinone oxidoreductase inhibitors from the Pathogen Box. Genes 2019, 10, 471. [CrossRef] [PubMed]

59. Deitsch, K.; Driskill, C.; Wellems, T. Transformation of malaria parasites by the spontaneous uptake and expression of DNA from human erythrocytes. Nucleic Acids Res. 2001, 29, 850-853. [CrossRef] [PubMed] 